\title{
Brain Localization and the Integrated Systems Hypothesis: Evidence from Broca's Region
}

\author{
Gerald C. Imaezue \\ Department of Special Education, University of Ibadan, Ibadan, Nigeria \\ Email: geraldimaezue@gmail.com
}

How to cite this paper: Imaezue, G.C. (2017) Brain Localization and the Integrated Systems Hypothesis: Evidence from Broca's Region. Journal of Behavioral and Brain Science, 7, 511-519. https://doi.org/10.4236/jbbs.2017.711036

Received: September 25, 2017

Accepted: November 5, 2017

Published: November 8, 2017

Copyright $\odot 2017$ by author and Scientific Research Publishing Inc. This work is licensed under the Creative Commons Attribution International License (CC BY 4.0).

http://creativecommons.org/licenses/by/4.0/ (c) (i) Open Access

\begin{abstract}
The human brain is a fascinatingly complex organ with specialized structures associated with distinct functions. Classical and recent studies on brain localization propose that Broca's area underpin expressive language and this has been generalized to explain brain functional organization. However, recent neuroimaging studies have shown that the Broca's area is an extended network that not only participate in its primary function-expressive language processing but in secondary functions-processing non-linguistic/nonverbal tasks as well. Also, there is hierarchical connectivity and interaction of Broca's region and different brain areas in underlying related primary functions. For this review, I start with revisiting the classical description of brain localization. I then discuss the neuroanatomy of language production and the role of Broca's region in language processing. I then highlight the participation of the Broca's area in non-linguistic tasks and non-primary linguistic tasks. Ultimately, I propose a novel hypothesis called integrated systems hypothesis. The integrated systems hypothesis is useful for guiding research on the multimodal role of specific localized integrated systems of the brain especially the role of the Broca's region in integrating linguistic and non-linguistic processing and how this facilitate language production.
\end{abstract}

\section{Keywords}

Brain Localization, Broca's Area, Broca's Region, Integrated System, Integrated Systems Hypothesis

\section{Introduction}

The human brain is a fascinatingly complex organ and it is the central organ of the human nervous system. The brain consists primarily of the cerebrum, cerebellum and brainstem which are made up of about 100 billion intricately con- 
nected neurons. Specific brain areas underpin various kinds of human behaviors and activities such as reasoning, learning, language, memory, muscle activities and so on [1]. The left hemisphere is the dominant center of language in most persons and damage to the language areas result in deficits in language processing. Studies of lesioned language areas of the brain as well as its correlated linguistic deficits (i.e. aphasia) has provided us a better understanding of localized organization of functions in the human brain which is a radical shift from the holistic theory of brain organization. Departing from classical aphasiology, the posterior inferior frontal gyrus was proposed to house language production. Recently, numerous studies have proposed different roles of Broca's area in language processing and findings from these studies have been generalized to explain brain connectivity. However, scant attention has been paid to the role of Broca's area in non-linguistic processing.

\section{Revisiting Classical Brain Localization}

Brain localization refers to the association of functions with particular areas in the brain. The hypothesis that different brain areas, such as the cerebrum and the cerebellum, may serve different functions dates back to the 18th century. The person cited to be the first to give a detailed write up about cortical localization of function is Emmanuel Swedenborg [1]. Swedenborg believed that the cerebrum was involved in understanding, thinking, judging and willing and he associated these functions with the cerebral cortex excluding the subcortical white matter. He rejected the idea of a unitary, indivisible structure of the cerebral cortex. Instead, he suggested that different functions are represented in different areas in the cerebral cortex. Such localization could account for why lesion to one part of the cerebral cortex might cause a paralysis, whereas damage to another cerebral loci might not affect movement but result in a loss of critical thinking. It could also explain why different functions, such as hearing and vision, are not confused with one another.

Organology (i.e. phrenology)-pseudoscience which studies the relationship between a person's character and the structure of the skull, created by Franz Joseph Gall (1758-1828), proposed that different regions in the human brain have localized functions and may very well be correlated with different behaviors. The crossing of pyramidal tracts was first observed by Gall, thus explaining the contra-lateral effect of lesion damage to the body [1]. Although he was interested in the study of individuals with speech deficits as a result of brain damage, he believed that data derived from such studies would only provide supporting data for his already established idea on brain localization based on bumps on the skull. Spurzheim extended Gall's idea by increasing the number of organs of mind, he reclassified the faculties, and discussed the implication of his finding for choosing a mate, educating children, selecting leaders, and the like. Spurzheim wrote numerous books about the idea and popularized the term "phrenology" - a word he did not introduce but preferred over Gall's term "organology" 
[2] [3]. However, his study was strongly criticized on anatomical grounds notably by Pierre Flourens (see Fourens [4] [5] [6]).

Paul Broca is credited for the clinical discovery of cortical localization of the human brain when he presented the report of "Leborgne" a 51-year-old man named who suffered a loss of speech associated with brain damage at the Anthropological Society of Paris. Leborgne expressed severe speech deficits as he was only able to produce a single syllable, tan, which he uttered twice in succession, regardless of the context. Subsequently, Broca came across another patient called "Lelong" who manifested speech deficits similar to his first case, but less severe. Lelong was able to utter five words instead of just one. During autopsy, Broca found that both patients had damage to the posterior inferior frontal gyrus on the surface of the left hemisphere. Broca reported several more case studies with similar anatomical correlations. Consequently, speech deficits due to lesion to the posterior inferior frontal gyrus on the surface of the left hemisphere became known as Broca's aphasia. Broca's research fortified belief in the existence of localized language centers in the brain as well as localization of functions in the brain. Paul Broca championed the cortical localization theory which has immensely contributed to our understanding of brain organization.

Hitherto, the theory of brain localization of function continues to gain support especially through converging evidence from neuroimaging and neuropsychological studies. Nevertheless many questions still remain to be answered. In the words of Finger [1]:

"Debates still flare about the precise boundaries of certain functional areas, whether certain areas should be subdivided, and the degree to which functional zones might overlap or shift after injury. Equally challenging has been trying to get agreement on the basic deficits observed after damage to specific parts of the cerebral cortex."

Contemporary research on brain localization shows that the brain localization theory today is much more complex and dynamic than the localization of macroscopic delineated centres postulated by Broca and other classical proponents of the theory, Understanding the neural correlates of language production as well as deficits after damage to these brain areas can give us a head start to a better understanding of brain organization.

\section{Neuroanatomy of Language Production}

Traditionally, Brodmann area (BA) 44 (pars opercularis of the left hemisphere) which corresponds with Broca's area was referred to as the neural seat of language production [7]. Recently, a good number of studies using neuroimaging technology provides us with better understanding of brain organization of language production. Foundas et al., [8] reported that BA45 (pars triangularis) is active in language production. Other studies have proposed a more extended language production system; For example, the concept of "Broca's complex", which includes BA44, BA45, and also BA47 was proposed by Hagoort [9] [10]. 
Lemaire et al. [11] proposed an "extended Broca's area" is activated in language production; Kadis et al. [12] proposed an language production network; Bernal et al. [13] proposed a Broca's network; and Ardila et al. [14], in a meta-analytic review study, proposed a "Broca's complex or frontal language production system" including not only left BA44 and BA45, but also BA46, BA47, partially BA6 (mainly its mesial supplementary motor area) and extending subcortically toward the basal ganglia and the thalamus (Figure 1).

Neuroimaging studies have shown that BA 44 is active in verbal fluency, speech comprehension, phonological processing, grammar processing and attention in speech [15] [16] [17] [18] [19]. Neuroimaging studies have also reported the participation of BA45 in language production in the following verbal functions: verbal fluency [20], grammar processing [19], phonological processing [21], lexical search [22], selective attention to speech [23], semantic memory retrieval [24] and reasoning processes [25].

Several studies have highlighted different proposals on the role of Broca's area in language processing which includes: construction of higher parts of the syntactic tree in speech production [26] [27]; binding the elements of language [9], selecting information among competing sources [28], generating/extracting action meanings [29]; sequencing motor/expressive elements [30]; cognitive control mechanism for the syntactic processing of sentences [31]; and verbal working memory [32]. Other proposals suggest Broca's area subregions might be compatible with the system of prefrontal hierarchical control such as distinct subregions engaging in language tasks based on phonological, syntactic and semantic processing [33] [34].

Interestingly, studies have also shown that these brain area implicated in the so-called "extended Broca's area or Broca's complex" underlie non-linguistic tasks as well as cognitive processes that facilitate linguistic and non-linguistic tasks. For example, neuroimaging studies have shown BA44 to be active in some other non-linguistic functions, such as action observation and motor acts,
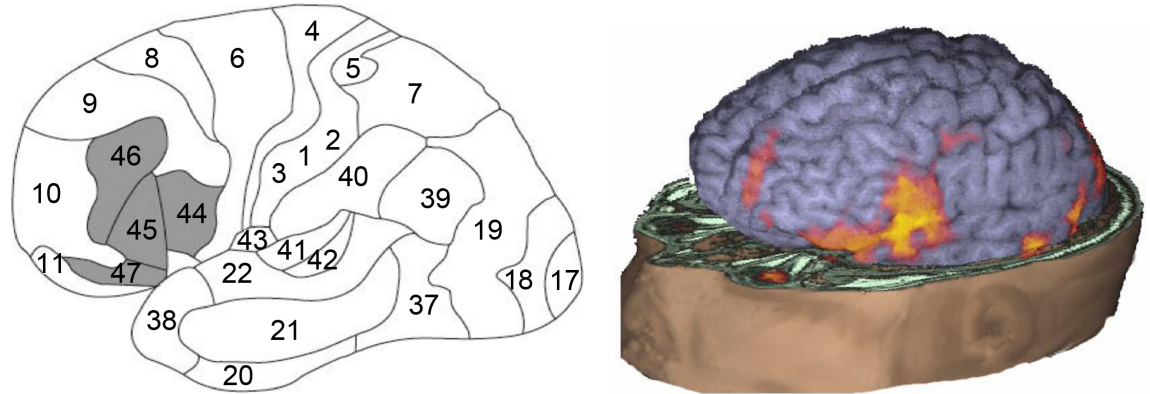

Figure 1. Broca's region according to Ardila et al., [14] includes BA44, BA45, BA46, BA47, mesial BA6 (supplementary motor area; not seen) and extending subcortically toward the basal ganglia and the thalamus (not seen). (Right panel) fMRI activation during speaking in a normal adult subject; observed is a wide activation including not only BA44 but also the surrounding areas, extending to the supplementary motor area (courtesy of the Department of Radiology-Nicklaus Children's Hospital). (From Ardila et al., 2016a). 
working memory, motor inhibition, mirror neuron systems, objectmanipulation, processing sequential sounds, and music enjoyment [18] [19] [35] [36] [37] [38]; syntactic working memory [39] [40], arithmetic processing [41]; tactile imagery [42]; motor programming [43]. Cabeza and Nyberg [44] review of neuroimaging studies of working memory supports the hypothesis that BA45/47 is recruited for selecting or comparing information, while BA9/46 might be more involved in the manipulation of information in working memory. The frontal areas adjacent to the classical Broca's area (BA44) as important for working memory in non-linguistic as well as linguistic tasks [45]. The activation of BA44 during different linguistic tasks results in a co-activation of some occipital lobe areas [13]. This means that language production abilities is directly related to other secondary functions such as action observation, syntax comprehension abilities, arithmetic processing, selection and comparison of information and manipulation of information in working memory which are underpinned by the Broca's area.

The Broca's area is a multifunctional brain region [13], although there is a consensus that it is primarily involved in processing of expressive language [9]. Bernal et al. [13] opined "that it is difficult to understand the multifunctional roles of Broca's area from the modern segregationist model of brain functions. The modern brain connectivity model propose multi-modular approaches explaining that BA44 may connect with different modules, depending on the specific task, yielding specific network configurations responsible for a given cognitive function. However, this view may explain better complex cognitive, behavioral and neuropsychological phenomena than simple localization models." The authors, in a landmark study to determine functional connectivity of Broca's area in expressive language, suggests that the multifunctionality of the Broca's area may be explained in part by the anatomical subdivisions but specific regions should connect in a specific manner producing a distinct task related network configurations. Bernal et al. [13] Broca's sub-anatomical differentiation hypothesis is consistent Amults et al. [46] histological autoradiography study that demonstrated different levels of cell receptors in the Broca's region. However, studies have also implicated the hierarchical connectivity and interaction of different localized areas in producing distinct task related network configuration(s), e.g. the role of the inferior frontal gyrus in speech perception as explained by Dual stream model of speech perception (see Hickok and Poeppel, [47] [48] [49]. Also, there is greater functional connectivity during intelligible speech comprehension between the fronto-temporal-parietal areas of the brain [50]. This implies the brain is made up of a different integrated system of distinct but overlapping neural connectivity in producing distinct task(s) related network configuration(s).

\section{Conclusions}

Classical and recent studies on brain localization propose that specific brain 
areas underpin functions e.g. the posterior inferior frontal lobe (i.e. Broca's area) is correlated with language production. However, recent neuroimaging studies have shown that the Broca's area is an extended network that not only participate in its primary function-language processing (e.g. expressive language) but participate in secondary functions-processing non-linguistic/nonverbal tasks (e.g. action observation, object manipulation, selection and comparison of information, manipulation of information in working memory etc.) and processing specific-linguistic tasks (e.g. phonological and syntactic processing). Also, there is hierarchical connectivity and interaction of brain areas in producing distinct task related network configuration(s). It is noteworthy to state that that though the brain is made up of an incredible network of neuronal connectivity, neurons are specialized for specific functions due to their connectivity patterns and response profiles. As discussed earlier, the connectivity profile of neurons may extend beyond one BA (e.g. an extended Broca's area) and this might be determined by the nature of the cell receptors in a brain area. This idea is consistent with Broca's sub-anatomical differentiation hypothesis.

In conclusion, I propose that the human brain consists of localized areas subserving specific integrated systems and each is made up of distinct but intra-dependent/overlapping neural networks underpinning specific secondary functions (e.g. comparing and sorting information and manipulation of object, syntactic and phonological processing) that integrate to perform a primary function (e.g. speech/language production). In essence, an integrated system in the human brain is a computational hub for specific primary tasks. This hypothesis also proposes that an integrated system do not work in isolation but connect with other integrated systems to produce related primary function(s), (e.g. the interaction of fronto-temporal-parietal areas of the brain in language).

In summary, the integrated systems hypothesis proposes that language production is a function of intra-neural-connectivity within a localized integrated system. The integrated systems hypothesis raises more questions than answers. It is useful for guiding research on the multimodal role of different localized integrated brain areas. This hypothesis might inform the development of effective approaches to enhance brain function and cognition in both the healthy and the neurologically impaired by taking into consideration the holistic function of integrated systems involved in language processing. This hypothesis should guide future studies on the role of the Broca's region in integrating linguistic and non-linguistic processing and how this facilitate language production.

\section{References}

[1] Finger, S. (2010) The Birth of the Localization Theory. In: Finger, S., Boller, F. and Tyler, K.L., Eds., Handbook of Clinical Neurology, Vol. 95 (3rd series) History of Neurology, 117-128.

[2] Young, R.M (1970) Mind, Brain and Adaptation in the 19th Century. Clarendon Press, Oxford.

[3] Finger, S. (2000) Minds behind the Brain. Oxford, New York. 
[4] Flourens, M.-J.-P. (1842) Recherches Experimentales sur les Proprie'te's et les Fonctions du Syste'me Nerveux dans les Animaux Verte'bre's [Experimental Research on the Properties and the Functions of the Nervous Systems in Vertebral Animals.] (2nd edn.). Baillie're, Paris.

[5] Flourens, M.-J.-P. (1846) Phrenology Examined (2nd Edition; de L Meigs C, trans.). Hogan and Thompson, Philadelphia.

[6] Flourens, M.-J.-P. (1864) Psychologie Compare'e. 2nd Edition, Garnier Fre'res, Paris.

[7] Ardila, A., Bernal, B. and Rosselli, M. (2016) Why Broca's Area Damage Does Not Result in Classical Broca Aphasia. Frontiers in Human Neuroscience, 10, 249. https://doi.org/10.3389/fnhum.2016.00249

[8] Foundas, A.L., Leonard, C.M., Gilmore, R.L., Fennell, E.B. and Heilman, K.M. (1996) Pars Triangularis Asymmetry and Language Dominance. Proceedings of the National Academy of Sciences, 93, 719-722. https://doi.org/10.1073/pnas.93.2.719

[9] Hagoort, P. (2005) Broca's Complex as the Unification Space for Language. In: Cutler, A., Ed., Twenty-First Century Psycholinguistics. Four Cornerstones, Lawrence Erlbaum Associates, Mahwah, 157-172.

[10] Hagoort, P. (2006) On Broca, Brain and Binding. In: Grodzinsky, Y. and Amunts, K., Eds., Broca's Region, Oxford University Press, Oxford, 242-253. https://doi.org/10.1093/acprof:oso/9780195177640.003.0015

[11] Lemaire, J.J., Golby, A., Wells, W.M., Pujol, S., Tie, Y., Rigolo, L., et al. (2013) Extended Broca's Area in the Functional Connectome of Language in Adults: Combined Cortical and Subcortical Single-Subject Analysis using fMRI and DTI Tractography. Brain Topography, 26, 428-441. https://doi.org/10.1007/s10548-012-0257-7

[12] Kadis, D.S., Dimitrijevic, A., Toro-Serey, C.A., Smith, M.L. and Holland, S.K. (2016) Characterizing Information Flux within the Distributed Pediatric Expressive Language Network: A Core Region Mapped through fMRI Constrained MEG Effective Connectivity Analyses. Brain Connect, 6, 76-83.

https://doi.org/10.1089/brain.2015.0374

[13] Bernal, B., Ardila, A. and Rosselli, M. (2015) Broca's Area Network in Language Function: A Pooling-Data Connectivity Study. Frontiers in Psychology, 6, 687. https://doi.org/10.3389/fpsyg.2015.00687

[14] Ardila, A., Bernal, B. and Rosselli, M. (2016b) How Localized Are Language Brain Areas? A Review of Brodmann Areas Involvement in Language. Archives of Clinical Neuropsychology, 31, 112-122. https://doi.org/10.1093/arclin/acv081

[15] Benson, F. and Ardila, A. (1996) Aphasia: A Clinical Perspective. Oxford University Press, Oxford.

[16] Heim, S., Eickhoff, S.B. and Amunts, K. (2008) Specialisation in Broca's Region or Semantic, Phonological, and Syntactic Fluency? Neuroimage, 40, 1362-1368.

[17] Kang, A.M., Constable, R.T., Gore, J.C. and Avrutin, S. (1999) An Event-Related fMRI Study of Implicit Phrase-Level Syntactic and Semantic Processing. Neuroimage, 10, 555-561. https://doi.org/10.1006/nimg.1999.0493

[18] Grossman, M., Cooke, A., DeVita, C., Chen, W., Moore, P., Detre, J., et al. (2002) Sentence Processing Strategies in Healthy Seniors with Poor Comprehension: An fMRI Study. Brain and Language, 80, 296-313. https://doi.org/10.1006/brln.2001.2581

[19] Sahin, N.T., Pinker, S. and Halgren, E. (2006) Abstract Grammatical Processing of Nouns and Verbs in Broca's Area: Evidence from fMRI. Cortex, 42, 540-562. 
[20] Abrahams, S., Goldstein, L.H., Simmons, A., Brammer, M.J., Williams, S.C., et al. (2003) Functional Magnetic Resonance Imaging of Verbal Fluency and Confrontation Naming using Compressed Image Acquisition to Permit Overt Responses. Human Brain Mapping, 20, 29-40. https://doi.org/10.1002/hbm.10126

[21] Heim, S., Eickhoff, S.B., Ischebeck, A.K., Friederici, A.D., Stephan, K.E. and Amunts, K. (2009) Effective Connectivity of the Left BA44, BA45, and Inferior Temporal Gyrus during Lexical and Phonological Decisions Identified with DCM. Human Brain Mapping, 30, 392-402. https://doi.org/10.1002/hbm.20512

[22] Fiebach, C.J., Friederici, A.D., Müller, K. and von Cramon, D.Y. (2002) fMRI Evidence for Dual Routes to the Mental Lexicon in Visual Word Recognition. Journal of Cognitive Neuroscience, 14, 11-23. https://doi.org/10.1162/089892902317205285

[23] Vorobyev, V.A., Alho, K., Medvedev, S.V., Pakhomov, S.V., Roudas, M.S., et al. (2004) Linguistic Processing in Visual and Modality-Nonspecific Brain Areas: PET Recordings during Selective Attention. Brain Research. Cognitive Brain Research, 20, 309-322.

[24] Düzel, E., Picton, T.W., Cabeza, R., Yonelinas, A.P., Scheich, H., et al. (2001) Comparative Electrophysiological and Hemodynamic Measures of Neural Activation during Memory-Retrieval. Human Brain Mapping, 13, 104-123.

https://doi.org/10.1002/hbm.1028

[25] Goel, V., Gold, B., Kapur, S. and Houle, S. (1998) Neuroanatomical Correlates of Human Reasoning. Journal of Cognitive Neuroscience, 10, 293-302. https://doi.org/10.1162/089892998562744

[26] Grodzinsky, Y. (2000) The Neurology of Syntax: Language Use without Broca's Area. Behavioral and Brain Sciences, 23, 1-21. https://doi.org/10.1017/S0140525X00002399

[27] Grodzinsky, Y. (2006) The Language Faculty, Broca's Region, and the Mirror System. Cortex, 42, 464-468.

[28] Thompson-Schill, S.L. (2005) Dissecting the Language Organ: A New Look at the Role of Broca's Area in Language Processing. In: Cutler, A., Ed., Twenty-First Century Psycholinguistics: Four Cornerstones, Lawrence Erlbaum Associates Inc., Mahwah, 173-190.

[29] Fadiga, L., Craighero, L., and Roy, A. (2006) Broca's Region: A Speech Area. In Broca's Region. In: Grodzinky, Y. and Amunts, K., Eds., Oxford University Press, New York, 137-152. https://doi.org/10.1093/acprof:oso/9780195177640.003.0009

[30] Ardila, A. and Bernal, B. (2007) What Can Be Localized in the Brain? Towards a "Factor" Theory on Brain Organization of Cognition. International Journal of Neuroscience, 117, 935-969. https://doi.org/10.1080/00207450600912222

[31] Novick, J.M., Trueswell, J.C. and Thompson, S.L. (2005) Cognitive Control and Parsing: Re-Examining the Role of Broca's Area in Sentence Comprehension. Cognitive, Affective, \& Behavioral Neuroscience, 5, 263-281. https://doi.org/10.3758/CABN.5.3.263

[32] Haverkort, M. (2005) Linguistic Representation and Language Use in Aphasia. In: Cutler, A., Ed., Twenty-First Century Psycholinguistics. Four Cornerstones, Lawrence Erlbaum Associates Inc., Mahwah, 57-68.

[33] Bookheimer, S. (2002) Functional MRI of Language: New Approaches to Understanding the Cortical Organization of Semantic Processing. Annual Review of Neuroscience, 25, 151-188. https://doi.org/10.1146/annurev.neuro.25.112701.142946

[34] Koechlin, E. and Jubault, T. (2006) Broca's Area and the Hierarchical Organization of Human Behavior. Neuron, 50, 963-974. 
[35] Lotze, M., Heymans, U., Birbaumer, N., Veit, R., Erb, M., Flor, H., et al. (2006) Differential Cerebral Activation during Observation of Expressive Gestures and Motor Acts. Neuropsychologia, 44, 1787-1795.

[36] Giraud, A.L., Kell, C., Thierfelder, C., Sterzer, P., Russ, M.O., Preibisch, C., et al. (2004) Contributions of Sensory Input, Auditory Search and Verbal Comprehension to Cortical Activity during Speech Processing. Cerebral Cortex, 14, 247-255. https://doi.org/10.1093/cercor/bhg124

[37] Zekveld, A.A., Heslenfeld, D.J., Festen, J.M. and Schoonhoven, R. (2006) Top-Down and Bottom-Up Processes in Speech Comprehension. Neuroimage, 32, 1826-1836.

[38] Koelsch, S., Fritz, T., VCramon, D.Y., Müller, K. and Friederici, A.D. (2006) Investigating Emotion with Music: An fMRI Study. Human Brain Mapping, 27, 239-250. https://doi.org/10.1002/hbm.20180

[39] Rämä, P., Martinkauppi, S., Linnankoski, I., Koivisto, J., Aronen, H.J. and Carlson, S. (2001) Working Memory of Identification of Emotional Vocal Expressions: An fMRI Study. Neuroimage, 13, 1090-1101. https://doi.org/10.1006/nimg.2001.0777

[40] Sun, X., Zhang, X., Chen, X., Zhang, P., Bao, M., Zhang, D., et al. (2005) Age-Dependent Brain Activation during Forward and Back Ward Digit Recall Revealed by fMRI. Neuroimage, 26, 36-47.

[41] Rickard, T.C., Romero, S.G., Basso, G., Wharton, C., Flitman, S. and Grafman, J. (2000) The Calculating Brain: An fMRI Study. Neuropsychologia, 38, 325-335.

[42] Yoo, S.-S., Freeman, D.K., McCarthy, J.J.III, and Jolesz, F.A. (2003) Neural Substrates of Tactile Imagery: A Functional MRI Study. Neuroreport, 14, 581-585. https://doi.org/10.1097/00001756-200303240-00011

[43] Amunts, K., Weiss, P.H., Mohlberg, H., Pieperhoff, P., Eickhoff, S., Gurd, J.M., et al. (2004) Analysis of Neural Mechanisms Underlying Verbal Fluency in Cytoarchitectonically Defined Stereotaxicspace-The Roles of Brodmann Areas 44 and 45. Neuroimage, 22, 42-56.

[44] Cabeza, R. and Nyberg, L. (2000) Imaging Cognition II: An Empirical Review of 275 PET and fMRI Studies. Cognitive Neuroscience, 12, 1-47. https://doi.org/10.1162/08989290051137585

[45] D’Esposito, M., Postle, B.R., Ballard, D. and Lease, J. (1999) Maintenance versus Manipulation of Information Held in Working Memory: An Event-Related fMRI Study. Brain and Cognition, 41, 66-86. https://doi.org/10.1006/brcg.1999.1096

[46] Amunts, K., Lenzen, M., Friederici, A.D., Schleicher, A., Morosan, P., Palomero-Gallagher, N., et al. (2010) Broca's Region: Novel Organizational Principles and Multiple Receptor Mapping. PLOS Biology, 8, e1000489. https://doi.org/10.1371/journal.pbio.1000489

[47] Hickok, G. and Poeppel, D. (2000) Towards a Functional Neuroanatomy of Speech Perception. Trends in Cognitive Sciences, 4, 131-138.

[48] Hickok, G. and Poeppel, D. (2004) Dorsal and Ventral Streams: A Framework for Understanding Aspects of the Functional Anatomy of Language. Cognition, 92, 67-99.

[49] Hickok, G. and Poeppel, D. (2007) The Cortical Organization of Speech Processing. Nature Reviews Neuroscience, 8, 393-402. https://doi.org/10.1038/nrn2113

[50] Abrams, D.A., Ryali, S., Chen, T., Balaban, E., Levitin, D.J. and Menon, V. (2013) Multivariate Activation and Connectivity Patterns Discriminate Speech Intelligibility in Wernicke's, Broca's and Geschwind's Areas. Cerebral Cortex, 23, 1703-1714. https://doi.org/10.1093/cercor/bhs165 